\title{
ESTRUCTURA Y VALIDEZ DE LAS NORMAS JURÍDICAS, SEGÚN RUPERT SCHREIBER
}

\section{Proposiciones indicativas y proposiciones normativas}

El lenguaje jurídico no sólo contiene normas y decisiones judiciales y administrativas, sino proposiciones de indole indicativa.

Proposiciones indicativas son las que enuncian algo acerca de la realidad. Las normativas, en cambio, "describen una situación del mundo que alguien tiende a realizar". En el caso de las jurídicas normativas el "portador" de tal voluntad es el poder del Estado. La diferencia entre las dos especies, dentro del marco de la sintaxis jurídica, "sólo debe ser esclarecida en lo que atañe a la estructura; la que concierne a la significación de tales proposiciones debe en cambio exponerse en la semántica del derecho". ${ }^{2}$

\section{Estructura lógica de las proposiciones indicativas individuales.}

Tanto las proposiciones indicativas como las normativas divídense, desde el punto de vista de su extensión, en individuales y universales (Allsätzen).

Las individuales atribuyen propiedades a individuos o expresan relaciones entre objetos.

Para la representación de las proposiciones de este grupo Schreiber se vale de dos clases de signos:

1. Constantes individuales, para los individuos de cada sector.

2. Predicados monádicos, que designan propiedades, y predicados poliádicos, que designan relaciones.

"Para objetos de los que debe aseverarse algo, se usan por regla general las minúsculas " $a$ ", " $b$ ", " "c", etc. A esta clase de signos se les da la denominación de constantes individuales. Las propiedades y las relaciones suelen simbolizarse por medio de las mayúsculas " $P$ ", " $Q$ ", " $R$ ", etc. Se les llama predicados. Los predicados que representan propiedades reciben el calificativo de monádicos, o simples, y los que representan relaciones, el de poliádicos, o relaciones". 3

Si $P$ designa, ejempligracia, la propiedad "comerciante", y a la persona Pedro Sánchez, la proposición "Pedro Sánchez es comerciante" se expresa simbólicamente asi:

1 Rupert Schreiber, Logik des Rechts, Springer-Verlag, Berlin, 1962, pág. 15.

2 Schreiber, op. cit., pág. 15.

3 Schreiber, op. cit., pág. 15. 
Si en el caso de la proposición relacional "Pedro Sánchez paga a Juan Pérez mil pesos" empleamos los signos $a$ para Pedro Sánchez, $b$ para Juan Pérez y $R$ para la relación "paga mil pesos", la expresión simbólica de tal proposición será, según Schreiber:

$$
R(a, b)
$$

Para representar, por medio de la misma estructura, todas las proposiciones individuales relativas al pago de una cantidad entre dos personas, hay que hacer uso de tres términos. Si $a$ significa Pedro Sánchez; $b$, Juan Pérez; $s$, la suma pagada y $R(\ldots, \ldots, \ldots)$ la relación "paga a $\ldots$. la suma de ...", la fórmula es

$$
R(a, b, s)
$$

Las expresiones anteriores son indispensables no sólo para la comprensión de las proposiciones enunciativas; "más importantes resultan aún para el desarrollo de la estructura de las normativas, ya que éstas presuponen la notación de las otras. Ello vale asimismo para lo que en seguida diremos de las indicativas universales". ${ }^{4}$

\section{Estructura lógica de las proposiciones indicativas universales}

"Proposiciones universales son las que valen para todos los individuos de cierto sector". ${ }^{5}$

Las de este grupo dividense, como antes se dijo, en indicativas y normativas.

Las indicativas contienen aserciones generales sobre la realidad, y en el ámbito de las ciencias físicas reciben el nombre de leyes de la naturaleza. Las universales normativas "regulan una pluralidad de casos", y en la órbita del derecho se llaman normas juridicas. Estas últimas no son las únicas proposiciones normativas universales; "tienen también tal carácter los preceptos que los padres dan a sus hijos o las cláusulas de una convención". ${ }^{6}$

De una proposición indicativa como la simbolizada por $P(a)$ podemos obtener otra universal si eliminamos la constante (a) para obtener una expresión de la forma $P(\ldots)$, que puede llenarse con cualquier constante individual. Pero si en vez de dejar vacío el lugar de la constante, introducimos la variable $x$, obtendremos la expresión

$$
P(x)
$$

Para indicar que la variable puede ser sustituida por las constantes refe-

\footnotetext{
4 Schreiber, op. cit., pág. 17.

5 Schreiber, op. cit., pág. 18.

6 Schreiber, op. cit., pág. 18.
} 
ridas a todos los individuos del correspondiente sector, se introduce el cualtificador universal ' $(x)$ ':

$$
\text { (x) } P(x)
$$

O sea: "para toda $x, x$ es $P$ ". O, más claramente dicho: "para toda $x$ vale que $x$ tiene la propiedad $P$ ". "Esta notación ofrece, sobre la que encierra lugares vacíos, la ventaja de que la variable puede ser ligada. Por ejemplo, la expresión

$$
\text { (x) }(y) R(x, y) \text {, }
$$

significa: 'para toda $x$ y toda $y$ vale que $x$ tiene con $y$ la relación $R$ '. De este modo pueden subordinarse a $x$ y a $y$ elementos de diferentes sectores." 7

\section{Estructura lógica de las resoluciones juridicas}

Al grupo de las proposiciones normativas pertenecen, con el carácter de proposiciones individuales, las que forman el subgrupo de las resoluciones juridicas.

Por resoluciones juridicas entiende Schreiber las proposiciones que dan expresión a un acto de voluntad del poder jurisdiccional o de cualquier otro órgano del Estado, si tales proposiciones se fundan en una norma de derecho.

"Las resoluciones jurídicas son proposiciones normativas de naturaleza individual, ya que regulan casos singulares, esto es, valen para individuos determinados in concreto." 8

Al hacer el análisis de las resoluciones jurídicas, Schreiber se sirve del ejemplo utilizado en conexión con las proposiciones indicativas individuales. Cuando la proposición "Pedro Sánchez paga a Juan Pérez mil pesos" aparece en un fallo judicial, su tenor es: "Pedro Sánchez es condenado a pagar mil pesos a Juan Pérez." "Si llamamos a las partes, como se acostumbra en las sentencias, actor y demandado, habrá entonces que decir: 'Se condena al demandado a pagar al actor la suma de mil pesos.' Sin alterar su sentido, podemos modificar de esta guisa el tenor de la resolución: 'Es conforme a derecho: el demandado paga al actor la suma de mil pesos" "...

"Formulemos ahora la misma proposición de manera general: 'Es conforme a derecho: el demandado realiza en favor del actor la prestación $r$ '. Al sustituir 'el demandado' por ' $a$ '; 'el actor', por ' $b$ ' y 'la prestación' por ' $z$ ', obtenemos el siguiente resultado:

Es conforme a derecho: $R(a, b, r) . "$

"Si prescindimos del contenido significativo de la expresión 'Es confor-

7 Schreiber, op. cit., pág. 18.

8 Schreiber, op. cit., pág. 24. 
me a derecho', y la representamos por medio del simbolo ' $N$ ', la fórmula de 'Es conforme a derecho: el demandado realiza en favor del actor la prestación $x^{\prime}$, será ésta:

$$
N[R(a, b, r)] . " 9
$$

Schreiber sostiene que la resolución jurídica encierra como núcleo la proposición indicativa $R(a, b, r)$. "Esta proposición, expresada de modo completo, asume la forma $V[R(a, b, I)]$. Pues lo que en realidad significa es que la proposición de la forma $R(a, b, r)$ es verdadera." 10

Al comparar la expresión $V[R(a, b, I)]$ con la "forma normal" de las resoluciones jurídicas $N[R(a, b, I)]$, advertimos que su estructura es la misma. Lo úniço que cambia es la valoración de cada una. Las posiciones indicativas son valoradas como "verdaderas" o "falsas" y las resoluciones jurídicas como "conformes a derecho" o "no conformes a derecho".

"La significación de este isomorfismo entre proposiciones indicativas individuales y resoluciones jurídicas sólo se destacará en todo su alcance al hacer el análisis de las normas jurídicas. Pues si las proposiciones individuales indicativas y normativas tienen igual estructura, cabe conjeturar que las resoluciones pueden subordinarse a las normas jurídicas del mismo modo en que las proposiciones indicativas individuales se subordinan a las indicativas universales." 11

\section{Estructura lógica de las normas jurídicas}

Las formas lógicas de los preceptos jurídicos deben estar constituidas de tal manera que podamos derivar de ellas el esquema proposicional de las resoluciones judiciales y administrativas. Partiendo de la estructura de las últimas es posible obtener la de las normas del derecho, así como, partiendo de la de las proposiciones indicativas individuales, obtuvimos la de las correspondientes proposiciones universales.

La forma $R(a, b, x)$ se convierte en la de una proposición universal, si sustituimos las constantes individuales ' $a$ ', ' $b$ ', ' $I$ ', por las variables ' $x$ ', ' $y$ ' y ' $z$ '. Se obtiene así la fórmula

$$
R(x, y, z) \text {. }
$$

"Esta proposición universal tiene un alcance demasiado amplio. $x$ e $y$ pueden ser cualquier individuo, es decir, un hombre, un animal o una cosa. Pero las resoluciones jurídicas, que atribuyen derechos o exigen una acción o una omisión, las limitamos siempre a las personas, individuales o colectivas. Por ello hay que restringir, consecuentemente, el alcance de las variables. Si re-

9 Schreiber, op. cit., pág. 25.

10 Schreiber, op. cit., pág. 26.

11 Schreiber, op. cit., pág. 26. 
presentamos por medio del predicado $P$ la propiedad que consiste en ser persona física o moral (en sentido jurídico), entonces tiene que valer para $x: P$ $(x)$, y para $y: P(y)$. La relación $R(x, y, z)$ vale, pues, solamente para las $x$ y las $y$ que cumplan la condición $P(x)$ y $P(y)$."12

Utilizando diversos ejemplos, Schreiber estudia la estructura de las obligaciones legales y contractuales. Para exhibir la de las legales, verbigracia, ejemplifica con la norma del parágrafo 812 del Código Civil Alemán $(B G B)$ : "Quien, por prestación de un tercero o en cualquiera otra forma, recibe algo sin fundamento legal en perjuicio de un tercero, está obligado a la devolución." El predicado "recibe algo", tiene, en el caso del ejemplo, el añadido "por prestación de un tercero o en cualquiera otra forma". Este añadido no supone una limitación, sino un esclarecimiento. Y si todos los casos en que por prestación de un tercero o en cualquiera otra forma alguien se enriquece sin fundamento legal caen bajo la disposición del $\S 812$ del $B G B$, el añadido puede suprimirse, sin restringir o ampliar la significación del texto. Podemos, pues, expresar así el mencionado precepto: "Quien en perjuicio de un tercero recibe algo sin fundamento legal, está obligado a la devolución." 13

La estructura lógica resulta más clara si modificamos la proposición de esta manera: "Cuando un bien pasa de una persona a otra sin fundamento legal, la que lo recibe está obligada a la devolución." Lo que, simbólicamente, puede expresarse asi:

$$
G(x, y, w)
$$

O sea: "El bien $w$ pasa de $x$ a $y . "$ La letra $G$ expresa, en el caso, la relación que consiste en que una cosa pase de un sujeto a otro.

En cuanto a la determinación "sin fundamento legal", no puede añadirse como elemento de la proposición, "porque desde el punto de vista lógico aquella determinación es independiente". ${ }^{14}$ "Sin fundamento legal" significa, en realidad, que no existe la obligación de que el bien $w$ pase de $x$ a $y$. Esto se puede formular de la siguiente manera:

$$
\bar{N}[G(x, y, w)]
$$

Que se lee: "No hay ninguna proposición que declare conforme a derecho que el bien $w$ pase del patrimonio de $x$ al patrimonio de $y . "$

La fórmula de la cónsecuencia jurídica: "el que recibe el bien está obligado a la devolución", se simboliza de este modo:

$$
N[H(y, x, w)]
$$

$H(y, x, w)$ significa la devolución del bien $w$ por $y$ a $x$. Luego $N\left[\begin{array}{l}H \\ y\end{array}\right.$, $\boldsymbol{x}, w)$ ] quiere decir: "Es conforme a derecho que $y$ devuelva a $x$ el bien $w . "$

12 Schreiber, op. cit., pág. 27.

13 Schreiber, op. cit., pág. 28.

14 Schreiber, op. cit., pág. 28. 
Habiendo reducido a fórmulas los elementos de la norma jurídica sobre enriquecimiento sin causa, para obtener la expresión simbólica completa del $\$ 812$ del $B G B$ basta con usar la conectiva de la implicación. La fórmula total resulta entonces:

$$
\{G(x, y, w) . \vec{N}[G(x, y, w)]\} \rightarrow N[H(y, x, w)] .
$$

O sea: "Dados los supuestos $G(x, y, w)$ y $\bar{N}[G(x, y, w)]$, vale la consecuencia juridica $N .[H(y, x, w)]$.

\section{Proposiciones lógicamente determinadas}

El estudio de las proposiciones lógicamente determinadas no pertenece a la sintaxis, sino a la semántica del derecho. "Por sistema semántico del lenguaje jurídico hay que entender un conjunto de determinaciones que ofrece, para cada proposición del mismo lenguaje, el criterio que permite determinar cuándo tal proposición tiene y cuándo no tiene validez." 15

Normalmente, observa Schreiber, el sistema semántico sólo da reglas sobre la verdad o la falsedad de las proposiciones. Dentro del ámbito de las ciencias de lo real el problema consiste simplemente en establecer la conformidad de las proposiciones con la realidad, por aplicación del correspondiente criterio epistemológico. Esto no siempre es posible en la órbita del derecho, porque las "proposiciones típicas" del lenguaje jurídico son normas de conducta, que no pueden ser calificadas del mismo modo que las proposiciones indicativas, esto es, como "verdaderas" o "falsas". Las normas de que tratamos no son "inmediatamente verificables". A fin de establecer si una proposición vale en derecho "hay que tomar en cuenta el procedimiento a través del cual las normas jurídicas adquieren validez". ${ }^{16}$ Y aun cuando para determinar si son válidas es menester recurrir a hechos observables, "la relación de esas normas con la realidad es diferente de la de las proposiciones indicativas". ${ }^{17}$

A la categoría de proposiciones formada por las normas y las resoluciones administrativas y judiciales no pueden aplicársele los valores "verdadero" y "falso".

Lo que debemos establecer, en conexión con ellas, es si tienen o no validez jurídica (Rechtsgültigkeit). Para designar tal propiedad, Schreiber se sirve de las expresiones "es conforme a derecho" o "vale en derecho".

Cuando a una proposición del lenguaje jurídico se coordina el valor "es conforme a derecho", o el valor "verdadero", la proposición tiene validez.

15 Schreiber, op. cit., pág. 63.

16 Schreiber, op. cit., pág. 63.

17 Schreiber, op. cit., pág. 63. 
Válido es, por tanto, "el concepto superior" para "es conforme a derecho" y "es verdadero". 18

Una clase especial de todo lenguaje es la constituida por las proposiciones lógicamente válidas. A ella pertenecen las proposiciones lógicamente verdaderas y las lógicamente válidas, en el sentido jurídico del término.

De una proposición indicativa decimos que es lógicamente verdadera cuando de la simple aplicación de las reglas semántiças se sigue que es verdadera; decimos que es falsa, cuando de la simple aplicación de tales reglas se sigue su falsedad. La proposición indicativa " $A$ ha herido a $B$ o $A$ no ha herido a $B$ " es lógicamente verdadera, porque para establecerlo basta con hacer uso de la tabla de verdad que corresponde a la disyunción. ${ }^{19}$

$\mathrm{Ni}$ las proposiciones lógicamente verdaderas ni las lógicamente falsas dicen nada acerca de lo real. "Si un acusado sostiene, por ejemplo, que en el momento de la comisión del delito estaba en Munich, y asegura que al mismo tiempo se encontraba en Londres, su declaración es falsa en alguna formạ, y para establecer su falsedad no se necesita ninguna prueba." 20

Como en la sintaxis del lenguaje los signos ' $v$ ' y ' $f$ ' no tienen ninguna significación, es posible, prosigue Schreiber, interpretarlos en dos distintas formas, la referida a proposiciones indicativas y la referida a proposiciones normativas. Dado que estas especies sólo difieren en lo que atañe a su interpretación semántica, el método de las matrices puede aplicarse a las proposiciones normativas. Si para el valor "es conforme a derecho" empleamos

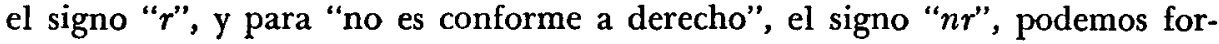
mar tablas de validez aplicables a las normas. Ejemplo: "el asesino debe ser castigado y no debe ser castigado con prisión perpetua". Schreiber simboliza la proposición "el asesino debe ser castigado con prisión perpetua" por medio de la letra " $p$ ", y para la contradictoria se vale del símbolo " $\bar{p}$ ". Empleando la tabla de validez que corresponde a la conjunción obtiene el siguiente resultado:

\begin{tabular}{|c|c|c|}
\hline $\mathrm{p}$ & $\overline{\mathrm{p}}$ & $p \cdot \bar{p}$ \\
\hline$r$ & $n r$ & $n r$ \\
$n r$ & $r$ & $n r$ \\
\hline
\end{tabular}

"Lo que vale para las normas jurídicas aisladas, en lo que respecta a 18 Schreiber, op. cit., pág. 69 . 19 Schreiber, op. cit, pág. 64 . 20 Schreiber, op. cit., pág. 64 . 
su determinación lógica, vale también para los sistemas jurídicos. Un sistema que contiene una contradicción es lógicamente inválido $y$, por tanto, también jurídicamente inválido. Es posible que ninguna de las normas que en su conjunto son lógicamente inválidas sea, individualmente considerada, lógicamente inválida. Por eso podemos, partiendo de una selección correcta, construir un sistema libre de contradicciones. Cuál de los sistemas no contradictorios es, también, jurídicamente válido, no puede decidirse de acuerdo con leyes lógicas." 21

7. Interpretación y verificación de las proposiciones indicativas individuales

En conexión con el problema que consiste en establecer cómo ha de investigarse el contenido de verdad de las proposiciones indicativas, Schreiber parte del siguiente postulado: la verdad o falsedad de las proposiciones indicativas depende de la percepción. Las propiedades y relaciones con que describimos la realidad han de ser observables, ya inmediatamente, ya de manera mediata.

Una propiedad o relación es observable, en relación con el lenguaje jurídico, cuando las personas en cuyo juicio debe apoyarse la proposición indicativa están en condiciones de decidir, fundándose en lo observado por ellas, si la proposición que afirma de un objeto tal o cual propiedad o relación es o no verdadera.

En el caso de las proposiciones indicativas individuales, la verificación puede basarse ora en observaciones propias, ora en observaciones ajenas (inspección ocular o declaraciones de testigos, por ejemplo).

"A las pruebas de inspección ocular pertenece también la de documentos, en la medida en que el tribunal tiene conocimiento de la existencia de un trozo de papel en que aparece determinado texto. Si la autenticidad del documento es discutida, la prueba se extiende a la recepción de testimonios o a la aplicación de proposiciones empíricas de índole general." 22

\section{Interpretación y verificación de proposiciones empiricas generales}

A1 hacer el análisis semántico de las proposiciones empíricas generales hay que recurrir a la interpretación de las indicativas individuales, puesto que la proposición universal sólo es verdadera cuando las correspondientes individuales lo son. $\mathrm{Y}$ a la inversa: si la de índole general es verdadera, también son verdaderas las individuales que de ella derivan.

La prueba de que todas las individuales derivables de una proposición empírica general son verdaderas sólo es posible cuando el número de las primeras es limitado.

21 Schreiber, op. cit., pág. 66.

22 Schreiber, op. cit., pág. 69 . 
"Las proposiciones empiricas universales exigen un número indefinido de constantes individuales. Aun cuando se intentara limitar el conjunto de las constantes, nunca podriamos verificar todas las proposiciones individuales contenidas en la universal, porque las más importantes son las que describen acontecimientos futuros." 23

En lo que respecta a la falsedad de las empíricas generales puede, en cambio, establecerse una condición muy clara: basta que una de las proposiciones individuales sea falsa para invalidar la correspondiente proposición general.

La comprobación de la verdad de las proposiciones empíricas generales es siempre relativa. A las proposiciones empíricas generales mejor comprobadas se les da el nombre de leyes de la naturaleza; a aquellas cuyo grado de verificación es débil se les llama hipótesis. Mientras mayor sea el número de casos concretos en que la hipótesis concuerde con la realidad, sin que se presente ninguna instancia contraria, la hipótesis podrá en mayor grado considerarse comprobada.

"Es importante advertir que el grado de comprobación no sólo depende del número de casos corroborantes, sino también de los que en forma indirecta revelan la correspondencia de la ley con la realidad. Esta comprobación indirecta obedece a que generalmente las leyes naturales no son establecidas en forma aislada, sino que pertenecen a un sistema de legalidades cuya validez es recíprocamente dependiente. La ley natural que se examina puede, pues, ser comprobada por casos concretos corroborantes de otras que tienen conexión con la primera." 24

Al jurista puede resultarle difícil, en relación con el planteamiento de un caso concreto, resolver si tal o cual ley natural está o no comprobada; pero inevitablemente tiene que decidir si la acepta o no como premisa de sus razonamientos.

9. Interpretación y determinación de la validez de las resoluciones juridicas

Al hacer el estudio de la resolución jurídica en sentido lato, esto es, como proposición que regula un caso concreto, Schreiber toma como punto de partida la interpretación de la proposición indicativa individual. Volviendo al ejemplo: "Es conforme a derecho: Pedro Sánchez paga a Juan Pérez mil pesos", encontramos como núcleo la proposición indicativa individual "Pedro Sánchez paga a Juan Pérez mil pesos". Esta última encierra la descripción de un hecho. "Lo único que varía en el caso es el modo de las dos proposiciones. Por medio de la normativa no se afirma que el hecho sea verdadero, sino que es conforme a la ley. La cuestión consiste, pues, en

23 Schreiber, op. cit., pág. 72.

24 Schreiber, op. cit., pág. 73. 
explicar qué quiere significarse con los valores 'conforme a derecho' y 'no conforme a derecho'." 25

El predicado "es conforme a derecho" califica a cierta situación de hecho frente a otras, pero sin tomar en cuenta si se ha realizado o no.

A fin de explicar qué interpretación corresponde a las proposiciones que ostentan los predicados de que estamos hablando, introduce Schreiber su Deskriptionsthese, o "tesis de la descripción", según la cual "las proposiciones normativas pueden reducirse a proposiciones indicativas". $\mathrm{O}$, con otras palabras: las calificadas con los valores "es conforme a derecho" o "no es conforme a derecho", pueden traducirse a proposiciones calificadas con los valores "verdadero" y "falso".

Incidiendo en el ejemplo: "Es conforme a derecho: Pedro Sánchez paga a Juan Pérez mil pesos", podemos decir que la validez de tal proposición significa que si Pedro Sánchez no paga a Juan Pérez los mil pesos, éste tiene una vía jurídica para cobrarlos. Si la situación calificada como conforme a derecho no se realiza, el acreedor está facultado para demandar la ejecución forzosa. "Esta situación puede describirse en forma todavía más precisa por medio de proposiciones indicativas. Para ello habrá que dar formulación a acontecimientos que se añaden como ulteriores presupuestos de la discrepancia entre lo que es conforme a derecho y lo que realmente ocurre. Estos presupuestos son los que el derecho procesal enlaza a la actividad de los órganos del Estado. Después hay que formular las consecuencias atribuidas a esos presupuestos. Como tales consecuencias habrá, a fin de cuentas, que describir ciertas modificaciones de la situación real del mundo, esto es, acontecimientos observables." 26

Como la validez de las resoluciones jurídicas está en todo caso ligada a la ley, es decir, a proposiciones normativas de indole universal, a manera de conclusión afirmaremos que "una proposición normativa individual es conforme a derecho cuando, de acuerdo con las reglas deductivas, puede ser derivada de normas jurídicas válidas y de las correspondientes proposiciones indicativas verdaderas". 27

\section{Interpretación y determinación de la validez de las normas juridicas}

El contenido de la norma jurídica consiste, según Schreiber, en el contenido potencial de las proposiciones individuales derivables de ella. Podemos, pues, sostener que a cada norma de derecho corresponden todas las proposiciones normativas individuales que provienen de la inserción de las constantes del sector de las correspondientes variables en el lugar de es-

25 Schreiber, op. cit., pág. 76.

26 Schreiber, op. cit., pág. 77 .

27 Schreiber, op. cit., pág. 84. 
tas últimas. "Preséntase así como problema interpretativo el que consiste en averiguar qué constantes pertenecen al ámbito de las variables y de qué manera las notas no observables son definidas por notas observables. Las proposiciones normativas universales que encierran notas no observables y que no están definidas por notas observables, sea a través del uso lingüístico, sea por medio de disposiciones legales, no son normas juridicas válidas, ya que no tienen, desde el punto de vista lógico, el carácter de proposiciones normativas universales en sentido pleno. Son, en otras palabras, semánticamente incompletas. Se trata de las llamadas 'fórmulas vacias'." 28

En cuanto reducen las notas no observables a notas observables, las definiciones legales son obligatorias. En ausencia de ellas debe considerarse que el legislador tomó como fundamento el uso normal del lenguaje.

El contenido de las normas creadas por el legislador nunca está totalmente determinado. Siempre existe un margen de indeterminación que los órganos aplicadores tienen la misión de llenar. A ellos corresponde también establecer los límites de indeterminación del lenguaje jurídico, cuando el caso que examinan cae dentro de ese ámbito de indeterminación linguística.

Para resolver si la norma objeto de la tarea hermenéutica tiene validez, debemos inquirir, ante todo, si se dio cumplimiento a los requisitos formales de su proceso de creación. Ello exige verificar una serie de proposiciones indicativas acerca de tal cumplimiento. Y como la descripción del proceso legislativo está contenida en normas de derecho constitucional, "hay, teóricamente al menos, que reducir la validez de tales normas a proposiciones indicativas".29

Pero la vigencia de las normas jurídicas no depende sólo de la regularidad de su proceso de creación, ya que "es posible que dejen de ser válidas si se oponen a otras normas jurídicas".

Si no hubiese preceptos para la solución de las antinomias, sectores importantes del orden jurídico quedarían - por su carácter contradictorioeliminados del propio orden. "Esto se impide en la medida en que se introducen diferencias de rango entre las normas del derecho y se estatuye que en caso de oposición contradictoria la de superior jerarquía debe prevalecer sobre las de rango más bajo. Otras veces se dispone que la ley especial deroga a la general (lex specialis derogat legi generali), o que la posterior invalida a la precedente (lex posterior derogat legi priori)'.30

Seguidamente estudia Schreiber el problema de las lagunas. La solución de éste presupone que los conflictos de intereses de que conocen los órganos del poder público están en todo caso sujetos a normas. "Como hemos exigido para nuestro sistema que las proposiciones normativas individuales

28 Schreiber, op. cit., pág. 84 .

29 Schreiber, op. cit., pág. 87.

30 Schreiber, op. cit., pág. 87 . 
deriven siempre, con ayuda de reglas de inferencia válidas, de normas de derecho, el único camino para llenar las lagunas de la ley consiste en formular otras normas." 31

Esto puede hacerse de dos maneras. O bien se amplía una disposición ya existente a fin de que el caso que se juzga caiga bajo ella, o se trata de obtener una norma nueva, de la que habrá que derivar la soluciớn del asunto.

Schreiber sostiene que a este procedimiento de integración puede dársele el nombre de analogía, pero nunca el de inferencia analógica, ya que no consiste en inferir, sino en crear un nuevo precepto.

\section{Relación entre validez y eficacia de las normas juridicas}

Basándose en la Deskriptionsthese, nuestro autor examina el nexo entre validez y eficacia de las normas jurídicas.

Punto de partida de su examen es la doctrina kelseniana sobre el mismo tema.

De acuerdo con Kelsen, existen dos posiciones antitéticas frente a la cuestión. "Un extremo está constituido por la tesis de que entre la validez como deber ser y la eficacia como ser no hay relación ninguna, y que la validez es totalmente independiente de la eficacia. El segundo extremo es la tesis de que la validez del derecho se identifica con el otro atributo... La primera tesis es falsa, pues no puede negarse que un orden jurídico, lo mismo que una norma jurídica aislada, pierde su validez cuando deja de ser eficaz; y que entre el deber ser de la norma y el ser de la realidad natural media una relación en la medida en que la norma de derecho, para ser válida, tiene que ser establecida por un acto real. La segunda solución es falsa, pues no puede desconocerse que, como antes se mostró, existen múltiples casos en que ciertas normas jurídicas son consideradas como válidas, a pesar de que no son, o todavía no son, eficaces." 32

Según Schreiber, la segunda de las posturas extremas de que habla Kelsen es la única correcta, por lo que sus objeciones a dicha tesis carecen de fundamento.

Antes de demostrarlo - prosigue aquél- es menester percatarse de que la tesis encierra una imprecisión terminológica, pues en vez de afirmar que validez y eficacia son idénticas, hay que decir que son equivalentes. "No se trata, en efecto, de las mismas expresiones, sino de expresiones distintas con igual significado. También en este sentido las usa Kelsen." ${ }^{33}$ La tesis

31 Schreiber, op. cit., pág. 87 . obra.

32 Kelsen, Reine Rechtslehre, págs. 215 ss. Citado por Schreiber en la pág. 80 de su 33 Schreiber, op. cit., pág. 81. 
de la equivalencia quedará establecida si podemos probar que de la validez de las normas del derecho se sigue su eficacia, y de la eficacia de tales normas se sigue su validez.

Hay un pasaje de la Reine Rechtslehre en que Kelsen admite la indicada equivalencia, puesto que afirma que "Ia eficacia del orden jurídico como totalidad y la de una norma aislada son - lo mismo que el acto de creación normativa - condición de la validez; pero eficacia en el sentido de condición, por lo cual un orden jurídico como totalidad y una norma jurídica aislada no pueden ser vistas como válidas si han dejado de ser eficaces". ${ }^{34}$ Pero de la proposición "si una norma jurídica no es eficaz tampoco es válida", lógicamente sólo se sigue — comenta Schreiber- que cuando una norma es válida también es eficaz.

Kelsen contradice este aserto cuando dice, en el pasaje ya citado, que "existen múltiples casos en que ciertas normas de derecho son consideradas como válidas a pesar de que no son, o todavía no son, eficaces".

E1 mismo Kelsen pone el siguiente ejemplo: "Un tribunal que aplica inmediatamente una ley, luego de ser promulgada y antes de que el precepto tenga eficacia, aplica al caso concreto una norma válida." 35

Schreiber arguye, en cambio, que "en la medida en que el tribunal aplica la norma ofrece al propio tiempo un ejemplo de su eficacia. La norma es eficaz cuando entra en vigor, aun cuando no sea inmediatamente cumplida y aplicada. Pues aun cuando sea aplicada más tarde, làs consecuencias del acto violatorio se extienden al momento que inmediatamente sigue a la iniciación de la vigencia". ${ }^{38}$

Schreiber recuerda este otro texto de Kelsen: "Una norma jurídica no empieza a ser válida cuando es completamente eficaz, sino cuando lo es hasta cierto grado, vale decir, cuando en cierto grado es cumplida y aplicada. La posibilidad de su ineficacia, esto es, la de que en ciertos casos no se cumpla ni aplique, tiene que darse siempre. Precisamente en este punto aparece la diferencia entre norma jurídica y ley natural." 37

"Estos desarrollos - replica Schreiber- revelan una propiedad de las normas jurídicas, pero no hacen necesaria la distinción entre validez y eficacia. $\mathrm{Y}$ aquí tampoco descubrimos una diferencia entre norma jurídica $y$ ley de la naturaleza." ${ }^{3 s}$

34 Kelsen, Reine Rechtslehre, págs. 218 s. Citado por Schreiber en la pág. 81 de su libro. 35 Kelsen, Reine Rechtslehre, pág. 11. Citado por Schreiber en la pág. 82 de su Logik des Rechts.

36 Schreiber, op. cit., pág. 82 . estudio.

37 Kelsen, Reine Rechtslehre, pág. 92. Citado por Schreiber en la pág. 82 de su 38 Schreiber, op. cit., pág. 82. 
12. Examen crítico de la doctrina de Schreiber sobre la estructura y validez de las resoluciones $y$ las normas jurídicas

Hemos visto cómo para Schreiber, las proposiciones integrantes del lenguaje jurídico pueden -ser, según los casos, indicativas o normativas. Tanto las indicativas como las normativas se subdividen, desde el punto de vista de su extensión, en individuales y universales.

A la definición que Schreiber da de las indicativas nada hay que objetar. Discutible es, en cambio, la que ofrece de las normativas. De acuerdo con ella, tales proposiciones "describen una situación del mundo que alguien tiende a realizar".

Adviértase, ante todo, que nuestro autor atribuye a las del segundo grupo el carácter de proposiciones descriptivas, con lo que prácticamente las equipara a las de la otra clase.

Tratemos, con auxilio de un ejemplo, de entender su punto de vista. ¿En qué sentido asevera que las proposiciones normativas describen una situación del mundo que alguien tiende a realizar?...

Ejemplifiquemos con la norma del parágrafo 812 del $B G B$, de que el propio Schreiber se sirve cuando analiza la estructura de las obligaciones legales. ${ }^{39}$ De acuerdo con tal precepto, "quien, en perjuicio de un tercero, recibe algo sin fundamento legal, está obligado a la devolución".

Esta norma, como todas las de carácter abstracto, ${ }^{40}$ consta de dos elementos: supuesto y disposición. El supuesto, en el caso del ejemplo, es la hipótesis de que alguno, sin fundamento legal, reciba algo en perjuicio de un tercero. La disposición estatuye, en el propio caso, que el que recibe en esas condiciones está obligado a devolver lo que indebidamente recibió.

Si consideramos el primero de los dos elementos, resulta obvio que no se refiere a un hecho real de la experiencia jurídica. $O$, expresado en otros términos: no describe un hecho ya realizado; simplemente alude a la posibilidad de que alguien reciba algo, sin fundamento legal, en perjuicio de un tercero. Tenemos, pues, que vérnoslas con una hipótesis, no con una descripción. Ello es igualmente diáfano en lo que atañe al segundo elemento, porque, lejos de describir la conducta efectiva de un sujeto o de una categoría de sujetos, prescribe la que los miembros de la clase designada por el concepto "persona que sin fundamento legal recibe algo en perjuicio de un tercero", tienen el deber de observar, si el supuesto jurídico se realiza. ${ }^{41}$ Schreiber replicaría que la consecuencia jurídica puede realizarse a su vez, y que tal realización consistiría en la devolución de lo recibido ile-

39 Schreiber, op. cit., pág. 28.

40 Cfr. E. García Máynez, Lógica del Juicio Juridico, Fondo de Cultura Económica, México, 1955, cap. I, 2.

41 Cfr. E. García Máynez, Lógica del Juicio Juridico, cap. v, 3. 
galmente en perjuicio de otra persona. Si en lugar de considerar la norma genérica como juicio hipotético que hace depender de su supuesto el nacimiento de un deber, consideramos la conducta del que cumple lo prescrito por la disposición normativa, indudablemente podremos decir: I) que esa conducta "es conforme al derecho", puesto que implica el cumplimiento de la disposición aplicable; 2) que, en cuanto real o efectiva, puede ser des. crita por un juicio enunciativo; 3) que es el hecho que el creador del precepto "tiende a realizar". La "situación del mundo" a que alude la definición de Schreiber es, pues, el cumplimiento u observancia de la proposición normativa o, en el caso que al jurista especialmente interesa, de la norma de derecho. Según esto, la situación descrita por las proposiciones jurídicas generales de naturaleza normativa consiste en la obediencia $\longrightarrow$, para expresarlo de manera más general- en la eficacia de las mismas proposiciones. ¿Quién puede desconocer que el legislador pretende que sus leyes sean acatadas, y que el acatamiento es algo que cabe describir por medio de aserciones verificables?... Lo que Schreiber define no es, en realidad, la proporción normativa (susceptible, como tal, de observancia o inobservancia), sino la situación a que aspira quien tiene interés en la eficacia de lo prescrito. Pero como esa situación consiste en el cumplimiento de la norma, a fin de cuentas resulta que lo definido por Schreiber no es, como él cree, la proposición de indole normativa, sino la conducta que se ciñe o ajusta a ella.

La conducta prescrita, en el caso del ejemplo, no es susceptible de descripción, porque no pertenece al orden de lo real, sino al de lo meramente posible. El legislador no describe; impone deberes o concede facultades. Pero ni el deber de hacer (o de omitir), ni el derecho de hacer (o no hacer) algo, son conductas efectivas, sino simples posibilidades de acción o de omisión que, al realizarse, necesariamente ostentan, desde el ángulo visual de la norma, ya el signo positivo de lo permitido o facultado (si se trata de ejercicio de derechos), ya el signo negativo de lo prohibido (en el caso de inob. servancia de deberes).

El aserto de que el "portador" de esa voluntad a que la definición de Schreiber se refiere es el poder del Estado, tampoco nos parece feliz, porque, en primer término, el giro "voluntad del Estado" (o "del poder del Estado"), no designa un querer en sentido psicológico y, en segundo lugar, porque el propósito de los órganos legislativos de que algo valga como norma o, dicho con mayor rigor, la voluntad de aprobar determinados proyectos o iniciativas de ley, no se confunde con el contenido de los correspondientes preceptos, que en todo caso consiste en la imputación, a determinado antecedente, de tales o cuales consecuencias de derecho. $\mathbf{4 2}$

$42 \mathrm{El}$ objeto del procedimiento hermenéutico, en la órbita del derecho, es, como dice Helmut Hatz, la captación del sentido expresado por una proposición jurídica. "Ei comprender no se refiere aquí a un individuo", esto es, "a lo que alguien ha querido, sino 
De acuerdo con la tesis que comentamos, tanto las proposiciones indicativas como las normativas divídense, desde el punto de vista de su ámbito personal de validez, en individuales y universales. En cuanto a las juridicas de carácter normativo, Schreiber llama normas exclusivamente a las de índole universal, y a las individuales les da el nombre de resoluciones juridicas. Esta última designación la emplea en un sentido lato, que abarca lo mismo a las resoluciones judiciales que a las de naturaleza administrativa.

En lo que atañe a las resoluciones jurídicas, considera que en ellas existe siempre, como "núcleo", una proposición indicativa individual. En el caso del ejemplo: "Es conforme a derecho: 'Pedro Sánchez paga a Juan Pérez la suma de mil pesos' ", la proposición 'Pedro Sánchez paga a Juan Pérez la suma de mil pesos', no es prescriptiva, sino indicativa o descriptiva y, por ende, puede ser verificada como cualquier juicio enunciativo. El hecho que describe es el que en la terminología jurídica se llama "cumplimiento" o "pago", lo que demuestra que la proposición de que estamos hablando difiere radicalmente de la que expresa el sentido de una resolución como la del ejemplo, esto es, de aquella según la cual 'Pedro Sánchez debe pagar a Juan Pérez la suma de mil pesos'.

Independientemente de que las resoluciones juridicas nunca son formuladas como Schreiber pretende, conviene advertir que si en verdad pertenecen al grupo de las proposiciones normativas individuales, resulta contradictorio sostener que su núcleo es una proposición de naturaleza indicativa. $\mathrm{Al}$ proceder de este modo, Schreiber repite el error que reprochamos a su definición general de las proposiciones normativas, lo que, por otra parte, nada tiene de extraño, ya que su doctrina sobre la estructura lógica de las resoluciones judiciales $\mathrm{y}$-administrativas se basa en la mencionada definición general.

Nuestro argumento no queda invalidado por el hecho de que la proposición "Pedro Sánchez paga a Juan Pérez la suma de mil pesos" se halle precedida por las palabras: "Es conforme a derecho", porque la expresión completa "Es conforme a derecho: Pedro Sánchez paga a Juan Pérez la suma de mil pesos", lejos de exhibir la estructura de la resolución jurídica con que nuestro autor trata de ilustrar su tesis, en realidad presupone la existencia de tal resolución, esto es, la de la proposición normativa individual que le sirve de base y que sólo cabe expresar correctamente de esta guisa: "Pedro Sánchez debe pagar a Juan Pérez la suma de mil pesos." Precisamente porque, en el caso, tal resolución vale juridicamente, la proposición que describe el cumplimiento de lo ordenado está referida a una conducta que podemos calificar como "conforme al derecho".

a lo que cierto concepto, o la ley, 'quieren'". Pero, como el mismo autor lo explica, no se trata de un "querer" en sentido psicológico. Helmut Hatz, Rechtsprache und juristischer Begriff, W. Kohlhammer Verlag, Stuttgart, 1969, Erster Abschnitt, 2 y 3. 
En relación con el ejemplo hay, pues, que distinguir con claridad tres diferentes proposiciones, a saber: 1) la normativa individual constitutiva de la sentencia, según la cual "Pedro Sánchez debe pagar a Juan Pérez la suma de mil pesos"; 2) la indicativa individual que describe el hecho del pago, esto es, la que Schreiber considera como "núcleo" de la resolución jurídica, y 3) la que dice que "la proposición 'Pedro Sánchez paga a Juan Pérez la suma de mil pesos' es conforme a derecho". (En este tercer caso se trata, en realidad, de dos proposiciones, de las cuales una "califica" a la otra. La calificada o valorada corresponde al objeto-lenguaje; la otra, al metalenguaje de ese lenguaje. ${ }^{43}$ Pero ninguna de ellas se confunde con la constitutiva de la resolución legal.)

El mismo argumento es aplicable a la proposición que califica a otra como "no conforme al derecho". Si, volviendo al ejemplo, aseveramos que la proposición "Pedro Sánchez no paga a Juan Pérez la suma de mil pesos" "no es conforme a derecho", ello presupone que la conducta descrita por tal proposición es violatoria del deber impuesto a Pedro Sánchez por el fallo judicial. Este último sirve de base, en ambos casos, a las proposiciones que respectivamente califican con los valores "conforme a derecho" y "no conforme a derecho" a las que se refieren al cumplimiento y al incumplimiento del deber.

Al comparar la expresión $V[R(a, b, I)]$ con la "forma normal" de las resoluciones jurídicas $N[R(a, b, r)]$, Schreiber sostiene que su estructura es la misma, y que lo único que cambia es la valoración de cada una: "Las proposiciones indicativas son valoradas como 'verdaderas' o 'falsas', y las resoluciones jurídicas como 'conformes a derecho' o 'no conformes a derecho'." 44

Si examinamos con cuidado la fórmula que de la resolución jurídica da nuestro autor, fácilmente podremos percatarnos de que lo que en el caso se valora como "conforme a derecho" no es -como parecería inferirse de la cita precedente- la resolución misma, sino la proposición indicativa "Pedro Sánchez paga a Juan Pérez la suma de mil pesos". Hay, pues, incongruencia entre lo que la mencionada fórmula expresa y lo que Schreiber dice en el pasaje transcrito.

En cuanto las resoluciones jurídicas tienen o deben tener su fundamento en normas de derecho, de ellas cabe decir, cuando están debidamente fundadas, que son juridicamente válidas; pero, en tal hipótesis, lo que se califica de este modo no es la proposición que describe la eficacia de la resolución jurídica, sino la resolución juridica misma, que no es ni puede ser descriptiva de ningún hecho.

$\$ 3$ Sobre la necesidad de distinguir entre objeto-lenguaje y metalenguaje insiste el mismo Schreiber en el cap. I, sección 3, pág. 7, de su obra.

44 Schreiber, op. cit., pág. 26. 
Según Schreiber, "las formas lógicas de los preceptos jurídicos deben estar constituidas de tal manera que podamos derivar de ellas el esquema proposicional de las resoluciones judiciales y administrativas. Partiendo de la estructura de las últimas es posible obtener la de las normas del derecho; así como, partiendo de la de las proposiciones indicativas individuales, obtuvimos la de las correspondientes proposiciones universales".45

Por ello es que, al referirse a la estructura lógica del parágrafo 812 del $B G B$, comete Schreiber nuevamente el error de considerar que el "núcleo" de la consecuencia jurídica $N[H(y, x, w)]$, expresada por

$$
\{G(x, y, w) . \overline{\bar{N}}[G(x, y, w)]\} \rightarrow N[H(y, x, w)],
$$

es la proposición indicativa "el sujeto $y$ devuelve al sujeto $x$ el bien $w$ ".46 Pero, en el caso, tal proposición, simbolizada por $H(y, x, w)$, no corresponde a la disposición del $\S 812$ del $B G B$; simplemente describe el cumplimiento de la norma legal.

Al discutir la "interpretación y validez de las resoluciones jurídicas", Schreiber toma nuevamente como punto de partida su interpretación de las proposiciones indicativas individuales. En el caso de "Es conforme a derecho: Pedro Sánchez paga a Juan Pérez la suma de mil pesos", la proposición "Pedro Sánchez paga a Juan Pérez la suma de mil pesos" encierra la descripción de un hecho. "Lo único que varía en el caso es el modo de las dos proposiciones. Por medio de la normativa no se afirma que el hecho sea verdadero, sino que es conforme a la ley. La cuestión consiste, pues, en explicar qué quiere significarse con los valores 'conforme a derecho' y 'no conforme a derecho':" 47

Para explicarlo, Schreiber introduce, como el lector recuerda, la llamada Deskriptionsthese, según la cual "las proposiciones normativas pueden reducirse a proposiciones indicativas".48 En relación con el ejemplo, declara que la validez de la proposición "Es conforme a derecho: Pedro Sánchez paga a Juan Pérez la suma de mil pesos" significa que si Pedro Sánchez no paga a Juan Pérez los mil pesos, éste tiene una vía jurídica para cobrarlos. Si la situación calificada como conforme a derecho no se realiza, el acreedor está facultado para demandar la ejecución forzosa. "Esta situación puede describirse en forma todavía más precisa por medio de proposiciones indicativas. Para ello habrá que dar formulación a acontecimientos que se añaden como ulteriores presupuestos de la discrepancia entre lo que es conforme a derecho y lo que realmente ocurre. Estos presupuestos son los que el derecho procesal enlaza a la actividad de los órganos del Estado. Des-

45 Schreiber, op. cit., pág. 27.

46 Schreiber, op. cit., págs. 28 y 29.

47 Schreiber, op. cit., pág. 76.

48 Schreiber, op. cit., pág. 77 . 
pués hay que formular las consecuencias atribuidas a esos presupuestos. Como tales consecuencias tendremos, a fin de cuentas, que describir ciertas modificaciones de la situación real del mundo, esto es, acontecimientos observables." 49

Aun cuando es cierto - para seguir con el ejemplo- que si la situación calificada como conforme a derecho no se realiza, el acreedor está facultado para demandar al deudor, es incorrecto pretender que en ello consiste la validez de la proposición de que Schreiber se sirve como ejemplo, porque, según lo demostramos antes, tal proposición califica a la que describe la observancia del deber, mas no contiene ninguna referencia a la que enlaza al acto violatorio determinadas consecuencias de naturaleza procesal. Al referirnos no a la observancia, sino a la conducta opuesta, y calificarla como "no conforme al derecho", tampoco damos expresión a la norma, sino que, presupuestas su existencia y validez, nos limitamos a valorar negativamente el hecho del incumplimiento. Es verdad que, partiendo de los preceptos genéricos relativos a la acción y a la ejecución forzosa, podemos calificar positiva o negativamente los hechos conformes o contrarios a esos preceptos; pero, al hacerlo, lejos de explicar la validez de éstos, o de dar expresión a su estructura lógica, seguimos refiriéndonos a la conducta efectiva de los obligados y, para valorarla en una u otra forma, tenemos que presuponer la validez de las normas en que tal valoración se basa.

Si bien en los pasajes últimamente transcritos Schreiber hace consistir la validez de la proposición "Es conforme a derecho: Pedro Sánchez paga a Juan Pérez la suma de mil pesos" en la existencia de la vía jurídica de que el acreedor dispone para cobrar lo que se le adeuda, más adelante, en la misma sección $\mathrm{C}_{1}$ del capítuln consagrado a la semántica del derecho, ofrece un criterio distinto, pues al examinar la relación entre las resoluciones y las normas jurídicas, sostiene que la validez de aquéllas deriva "de la ley y el derecho", esto es, ya de preceptos legales, ya de normas de carácter consuetudinario..$^{50} \mathrm{Y}$, a manera de conclusión, asienta que "una proposición normativa individual es conforme a derecho cuando, de acuerdo con las reglas deductivas, puede ser derivada de normas jurídicas válidas y de las correspondientes proposiciones indicativas verdaderas". ${ }^{51}$

El pasaje anterior nos autoriza a sostener que Schreiber propone dos diversos criterios para determinar la validez de las resoluciones jurídicas. Por una parte, de acuerdo con la llamada Deskriptionsthese, afirma que la validez de las proposiciones normativas equivale a su eficacia, ${ }^{52}$ y que la significación de los valores "conforme a derecho" y "no conforme a derecho"

\footnotetext{
49 Schreiber, op. cit., pág. 77.

50 Schreiber, op. cit., pág. 83 .

51 Schreiber, op. cit., pág. 84.

52 Schreiber, op. cit., pág. 81.
} 
puede caracterizarse suficientemente por medio de proposiciones indicativas; por otro lado, según acabamos de verlo, refiere la validez de las resoluciones jurídicas a la de las normas genéricas de que tales resoluciones derivan.

En consonancia con este segundo criterio, para comprobar la validez de una resolución jurídica hay que establecer no sólo la de las normas en que se funda, sino la verdad de las proposiciones que describen los hechos condicionantes de las consecuencias de derecho. Es indispensable, además, aplicar correctamente las reglas del proceso deductivo. ${ }^{53}$

El problema referido a las resoluciones jurídicas remite, de acuerdo con este planteamiento, al de la validez de las normas que sirven de base al mencionado proceso.

Al discutir la segunda de las dos cuestiones, Schreiber vuelve a servirse de la Deskriptionsthese. Para resolver si una norma de derecho es válida, debemos, ante todo, cerciorarnos de que se ha dado cumplimiento a los requisitos formales de su proceso de creación. Ello puede establecerse verificando una serie de proposiciones indicativas. Hay que esclarecer, en otras palabras, "si el proceso legislativo efectivamente tuvo lugar. Pero como en la descripción de tal proceso están primeramente contenidas ciertas normas del derecho constitucional, habrá, teóricamente al menos, que referir su validez a proposiciones de índole indicativa".54

Los procesos conocidos con el- nombre de fuentes del derecho invariablemente se traducen en una serie de requisitos de cuyo cumplimiento depende, según las disposiciones reguladoras de tales procesos, la validez formal de las normas creadas a través de ellos. Si, por ejemplo, para que una iniciativa se transforme en ley, la Constitución de un país exige que el proyecto sea sucesivamente discutido y aprobado por las Cámaras; que el Poder Ejecutivo lo sancione; que el texto aprobado y sancionado se publique en el Diario Oficial, y que llegue la fecha de iniciación de la vigencia, el cumplimiento de todos estos requisitos, que determina la eficacia de las normas reguladoras del proceso legislativo, puede - precisamente por tratarse de hechos jurídicamente regulados- ser descrito por un conjunto de proposiciones de índole indicativa. Estas últimas describen esa sucesión de hechos y, al hacerlo, comprueban la realización de los supuestos condicionantes de la validez formal de las normas legislativamente creadas. En tal sentido cabe decir que las condiciones que en su conjunto integran el proceso de creación jurídica, constituyen las hipótesis de cuya realización depende el deber, impuesto a los órganos del Estado, de considerar los preceptos oriundos de las fuentes formales como parte integrante del orden en vigor. La validez: formal de los mismos dimana, en consecuencia, de la eficacia de las disposi-

53 Cfr. Schreiber, Logik des Rechts, Zweiter Teil, I, B, 2 a) y b) en donde estudia la regla de sustitución y la regla deductiva fundamental.

54 Schreiber, op. cit., pág. 87 . 
ciones reguladoras de las diversas fuentes de creación normativa, y tal validez puede establecerse por medio de proposiciones que describen los hechos en que tal eficacia se hace consistir.

Pero como los requisitos que integran cada uno de esos procesos (legislación, costumbre, etc.) no se refieren al contenido de las normas, sino exclusivamente a su modo de creación, decir que éstas son formalmente válidas ( $o$, en otros términos, que pertenecen al orden en vigor), en realidad implica que los órganos del poder público tienen el deber de aplicarlas, y que los particulares a quienes se destinan están obligados a cumplirlas. Precisamente porque el criterio de que estamos tratando es puramente extrinseco, queda abierta la posibilidad de que los sometidos al orden jurídico pongan en tela de juicio la validez intrinseca de éste. Pero, al hacerlo, la pauta que emplean no es, ni puede ser, la única que el Estado considera aplicable. ${ }^{55}$

El cumplimiento de los requisitos establecidos por las normas reguladoras de los procesos de creación jurídica es condición necesaria, mas puede no ser condición suficiente de validez de los preceptos creados de acuerdo con tales normas, ya que, como Schreiber lo indica, a menudo se exige que dichos preceptos no se opongan a otros de mayor rango. Si hay oposición contradictoria entre leyes de jerarquía diferente, la de rango superior prevalece sobre la otra.56 En casos como éste, la validez y aplicabilidad de la subordinada no dependen ya de la regularidad de su proceso de creación, sino de su congruencia con otros preceptos de mayor altura y, en último término, con la norma básica.

La validez, en el sentido juridico-positivo de este vocablo, obedece, según lo expuesto, ya a exigencias referidas a la forma de creación de los distintos

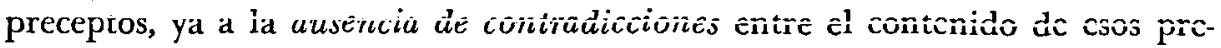
ceptos y el de otros de superior jerarquía.

En lo que atañe a las condiciones de la primera especie, no hay duda de que su cumplimiento puede ser descrito, como afirma Schreiber, por medio de proposiciones de naturaleza indicativa. Pero ello no significa que las proposiciones normativas o, en nuestro caso, las oriundas de las fuentes formales, puedan "traducirse" a proposiciones indicativas. Lo que debemos sostener, a la luz de nuestros análisis, es que la fuerza obligatoria de tales normas depende de la eficacia de las que regulan su proceso de creación. Si sabemos que los requisitos enumerados por las últimas quedaron cumplidos $o$, lo que es igual, si comprobamos la realización de los supuestos condicio-

55 Cfr. E. Garcia Máynez, "Validez formal y validez material en sentido jurídicopositivo, y validez objetiva o intrínseca en sentido axiológico", en Symposium sobre Derecho Natural y Axiologia, XIII Congreso Internacional de Filosofía, Centro de Estudios Filosóficos, México, 1963, págs. 83-99.

56 Cfr. E. García Máynez, Introducción a la Lógica Juridica, Fondo de Cultura Eco. nómica, México, 1951, Primera Parte, II. 
nantes de la validez de las primeras, estaremos en condiciones de afirmar que ésta ha quedado establecida. Las proposiciones de que nos servimos para describir la realización de tales supuestos no deben por tanto interpretarse como "traducción" de aquellas cuya validez investigamos, sino como proposiciones referidas al "fundamento" (o, mejor dicho, a la prueba del fundamento) de ese atributo.

En cuanto a la "concordancia" o "compatibilidad" de las normas de inferior rango con las de jerarquía superior, es obvio que puede también verificarse por medio de proposiciones-indicativas. Lo que éstas enuncian es que entre el contenido de los preceptos de menor y mayor altura no hay oposición. Mas para llegar a este resultado es indispensable interpretar previamente los textos de las correspondientes disposiciones.

En el caso de las resoluciones jurídicas, una vez establecida la validez de la norma que funge como premisa mayor de la inferencia, y formulado el juicio que comprueba la realización del supuesto legal de aquélla, la resolución (judicial o administrativa) constituye la conclusión del raciocinio. Cuando las reglas deductivas son correctamente aplicadas, ${ }^{57}$ de la validez de las premisas se sigue la de la proposición individual que resuelve la especie.

Conviene percatarse de que las proposiciones enunciativas de que solemos echar mano para describir los hechos que constituyen el fundamento de las normas y las resoluciones juridicas, y de las cuales colegimos, al ponerlas en relación con proposiciones normativas de indole general, la validez, en sentido jurídico-positivo, de esas normas y resoluciones, nada indican sobre la justicia o validez intrínseca, en sentido axiológico, de tales resoluciones y normas. 58

Si concluyo que una sentencia es válida en la medida en que - de acuerdo con las reglas de inferencia aplicables - deriva de premisas válidas, y para afirmar la validez de la norma genérica compruebo la realización de los supuestos de las disposiciones reguladoras del correspondiente proceso de creación jurídica, en realidad hago depender la validez de esa sentencia de la norma abstracta que le sirve de fundamento, como hago depender la de ésta de la de las normas de mayor altura que regulan su proceso de creación y, en último término, de los preceptos constitucionales a cuyo contenido deben ajustarse todas las disposiciones de inferior rango.

Lo expuesto prueba que el aserto de que una norma es válida, en sentido juridico-positivo, a fin de cuentas solamente implica: I) que, desde el punto de vista de los órganos del Estado, esa norma pertenece al orden vigente; 2) que su contenido es compatible con el de otras de jerarquía superior. Y como la validez de todos los preceptos de un orden jurídico en último término se hace dimanar, directa $o$ indirectamente, del nexo que guardan

57 Ver nota 53 .

58 Véase el estudio citado en la nota 55. 
con la norma básica, y ésta, por definición, no puede tener su razón de validez en otra de mayor altura, puesto que ella es la fundamental, no queda más remedio que, o bien presuponer que es válida, como lo hace Kelsen,59 o confesar que el problema de la validez jurídico-positiva encuentra aquí un límite infranqueable, por lo que necesariamente remite al de la justificación objetiva, en sentido axiológico, de los preceptos de cada ordenamiento.

Cuando el legislador cumple la tarea que la Constitución le impone, en todo caso se ve obligado a aplicar - dentro de los límites y de acuerdo con las directivas que la propia Constitución señala- una serie de pautas de valoración que en su mayor parte están sólo implícitas en las normas constitucionales, y debe luego adaptarlas a las peculiaridades de las situaciones que pretende convertir en objeto de regulación. De manera semejante, cuando se propone una reforma a las leyes en vigor, se discute la utilidad de determinados preceptos del orden jurídico o se pondera la justicia de un fallo judicial, a lo que se atiende no es a la validez jurídico-positiva de esa resolución o esos preceptos, sino a la bondad o justicia de su contenido.

Como lo indicamos en la parte final de la sección 11 de este artículo, la relación entre validez y eficacia de las normas del derecho puede también precisarse, según Schreiber, con ayuda de la Deskriptionsthese.

De las posturas extremas que Kelsen menciona en relación con este punto, ${ }^{60}$ Schreiber piensa que la única correcta es la segunda, es decir, la que tiende a la identificación de los dos atributos. Pero nuestro autor juzga que más que de identidad, debe hablarse de equivalencia. Si declaramos, con Kelsen, que la eficacia de todo orden jurídico, lo mismo que la de cualquiera de sus normas, es condición de validez del orden como totalidad y de los preceptos que lo forman, tendremos que admitir que "cuando una norma es válida también es eficaz".

Kelsen - prosigue Schreiber- contradice este resultado al sostener que "existen numerosos casos en que ciertas normas de derecho son consideradas como válidas, a pesar de que no son, o todavía no son, eficaces". ${ }^{61}$ Recordemos el ejemplo: "Un tribunal que aplica inmediatamente una ley, luego de ser promulgada y antes de que el precepto tenga eficacia, aplica al caso concreto una norma válida." 62 A esto contesta Schreiber que "la norma es eficaz cuando entra en vigor, aun cuando no se cumpla ni aplique. Pues aun cuando sea aplicada más tarde, las consecuencias del acto violatorio se extienden al momento que inmediatamente sigue a la iniciación de la vigencia".63

59 Cfr. H. Kelsen, "Natural Law Doctrine and Legal Positivism", que figura como apéndice de la obra General Theory of Law and State, Harvard Univeristy Press, 1945. 60 Cfr. Schreiber, op. cit., cita de Kelsen en la pág. 80.

61 Kelsen, Reine Rechtslehre, pág. 215, cita de Schreiber en la pág. 80 de su obra. 62 Kelsen, Reine Rechtslehre, pág. 11, cita de Schreiber en la pág. 82 de su libro. 63 Schṛeiber, op. cit., pág. 82. 
Esta réplica carece de fundamento. "Validez del derecho significa -como escribe Kelsen - que las normas jurídicas son obligatorias, que los hombres deben conducirse como éstas lo prescriben, y que están obligados a obedecerlas y a aplicarlas. Eficacia del derecho significa que los hombres efectivamente se conducen como, de acuerdo con tales normas, deben hacerlo, o que esas normas son efectivamente aplicadas y obedecidas. La validez es una cualidad del derecho; la llamada eficacia, un atributo del comportamiento real de los hombres y no, como el uso del lenguaje parece sugerirlo, del derecho mismo. El aserto de que el derecho es eficaz solamente significa que la conducta real de los hombres se ajusta a las normas de aquél. Validez y eficacia refiérense, por ende, a fenómenos radicalmente diversos." 64 Precisamente por ello reconoce Kelsen que los preceptos legales tienen validez desde el momento en que entran en vigor, aun cuando no sean inmediatamente cumplidos y aplicados. Para afirmar que son válidos, en sentido jurídico-positivo, basta, en efecto, comprobar estos dos extremos: a) que fueron creados en la forma establecida por las normas reguladoras del proceso de la legislación; $b$ ) que su contenido no se opone al de otros preceptos de jerarquía superior, señalados por la ley fundamental.

$\mathrm{Si}$ estos requisitos son condición necesaria y suficiente de validez, la eficacia de los preceptos oriundos de las fuentes formales nada añade al otro atributo. Argumentar que las leyes son eficaces desde la iniciación de su vigencia aun cuando no sean cumplidas ni aplicadas, porque las consecuencias del acto violatorio se extienden a ese momento, es una afirmación sin base, por la sencilla razón de que la consecuencia jurídica no puede ser anterior al hecho que la condiciona.

Kelsen está en lo justo cuando, de acuerdo con las premisas de su tesis, asevera que la posibilidad de la ineficacia, es decir, la de que en ciertos casos una norma no se cumpla ni aplique "tiene que darse siempre". ${ }^{65} \mathrm{Se}$ equivoca, en cambio, al asentar, en el mismo sitio, que la norma empieza a ser válida no cuando es completamente eficaz, "sino cuando lo es hasta cierto grado, es decir, cuando en cierto grado es cumplida y aplicada".66 Pero de este modo entra en contradicción con otro aserto suyo ya recordado por nosotros, el de que una ley es válida desde el momento en que entra en vigor, "aun cuando no sea, o todavía no sea, eficaz". ${ }^{67}$

Si la validez, en sentido jurídico-positivo, se hace depender de la regularidad del proceso de creación de las normas del sistema, y del hecho de que no sean incompatibles con otras de mayor jerarquía, a fin de cuentas

64 Kelsen, General Theory of Law and State, pág. 39.

65 Kelsen, Reine Rechtslehre, pág. 92. Cita de Schreiber en la pág. 82 de su Logik des Rechts.

66 Kelsen, Reine Rechtslehre, pág. 92. Citado en la pág. 82 de la obra de Schreiber.

67 Kelsen, Reine Rechtslehre, pág. 215. Citado en la pág. 80 del libro de Rupert Schreiber. 
resulta, como Kelsen lo reconoce en diversas obras, que la llamada "validez", en el sentido expuesto, no es otra cosa que la existencia de los preceptos jurídicos como partes de un orden que se declara "válido" precisamente en cuanto es "eficaz".

Que un ordenamiento sea eficaz "significa que los órganos y los súbditos del mismo se comportan, las más de las veces, conforme a las normas que lo constituyen. Considerado como un todo, un ordenamiento jurídico puede ser eficaz aun cuando una que otra norma que, según su propio sentido, debiera ser aplicada u obedecida, no lo sea en algunos casos. El principio de efectividad se refiere a todo un ordenamiento y no a normas jurídicas aisladas. Este principio es presupuesto por los juristas cuando interpretan el acto por el cual la primera constitución se establece como un acto de creación normativa y a la constitución como una norma jurídica. Como consecuencia de este principio, una constitución se origina en una autoridad lẹgítima a condición de que el ordenamiento jurídico creado sobre la base de tal constitución, sea eficaz como un todo". ${ }^{68}$

La relación entre validez y eficacia es, pues, distinta en el caso de un ordenamiento y en el de los preceptos que lo forman. La atribución de validez a un orden, considerado como totalidad, está condicionada por la eficacia normal de éste; la atribución de validez a los preceptos que lo integran, depende, en cambio, del cumplimiento de los requisitos de su proceso de creación y de la compatibilidad de su contenido con el de otros preceptos de mayor altura. Precisamente por ello cabe admitir, dentro del marco de la tesis kelseniana, que una norma puede ser válida "aun cuando no sea, o todavía no sea, eficaz".

La tesis de que el término "validez", en sentido jurídico-positivo, designa en realidad la "existencia" de la norma que se caiifica como "váiida", ha sido recientemente sostenida por Georg Henrik von Wright en su libro Norm and Action. ${ }^{69}$ Según este autor, el término de que hablamos puede entenderse, al menos, en dos distintas formas.

En un primer sentido, decir que una norma es válida equivale a declarar que existe. ${ }^{70}$

En un segundo sentido, validez significa "que la norma existe y, además, que existe otra que permitió a la autoridad de la primera expedir la segunda. Si decidimos llamar legal, o conforme a la ley, al acto de expedición, cuando hay una norma que lo permite, entonces podemos decir también

68 Kelsen, Los juicios de valor en el derecho, pág. 258 de la traducción de Guillermo García Máynez, en el volumen titulado La idea del derecho natural y otros ensayos, Editorial Losada, Buenos Aires, 1946.

69 Georg Henrik von Wright, Norm and Action. A Logical Enquiry. International Library of Philosophy and Scientific Method, London, Routledge \& Kegan Paul, 1969.

70 G. H. von Wright, op. cit., pág. 194. 
que validez, en el sentido que examinamos ahora, significa legalidad del acto de expedición".71

A la inversa, aseverar que una norma es inválida quiere decir -prosigue von Wright- que su expedición por determinada autoridad está prohibida por otra norma de mayor rango.

La consecuencia que el mismo autor deriva de este concepto de validez, al que llama "relativo", es que la norma suprema (o "soberana", como él dice) no puede ser válida ni inválida (ya que no podemos buscar su fundamento en otra de jerarquía superior).

La existencia de nexos de supra y subordinación entre las normas de un orden jurídico permite atribuir igualmente a éstas, según el propio von Wright, una validez intrasistemática o absoluta. Declarar que una norma es "absolutamente válida" significa que podemos encontrar su fundamento, de modo directo o indirecto, en otra de carácter "soberano". Pero como esta referencia a la suprema norma se define por medio de la noción de "validez relativa", la de "validez absoluta" es secundaria en relación con la otra, o la presupone. ${ }^{72}$

Los anteriores desenvolvimientos no dejan ninguna duda sobre el hecho de que el término "validez", en la acepción jurídico-positiva del vocablo, nada tiene que ver con el problema referido a la "justificación" de lo que las normas de un ordenamiento permiten, prohiben $\mathbf{u}$ ordenan a sus destinatarios. Si el "sentido" de aquéllas consiste en estatuir lo que, en las circunstancias descritas por el supuesto legal, debe ser jurídicamente, la cuestión relativa a la validez intrínseca o, en otras palabras, a la justificación de lo prescrito, no queda en modo alguno resuelta cuando se comprueba que la prescripción que se examina forma parte del orden en vigor. Establecida su pertenencia a éste, sigue en pie el problema de su validez objetiva, precisamente porque la circunstancia de que "exista" como parte de un orden jurídico no depende de su bondad o justicia, sino de requisitos puramente extrinsecos.

En otras palabras: establecer la validez jurídico-positiva de una norma de derecho es indispensable cuando se quiere comprobar si los órganos del poder público están obligados a aplicarla a los casos que su supuesto describe; pero tal comprobación, de la que para tales órganos depende la fuerza obligatoria del precepto, no puede impedir que los particulares, e incluso esos mismos órganos, se planteen el problema, radicalmente diverso, de si lo que el precepto exige está o no "justificado", en el sentido axiológico de la expresión. Y es claro que semejante problema sólo puede resolverse cuando se tiene conocimiento de los valores que, en conexión con las

71 G. H. von Wright, op. cit., pág. 195.

72 G. H. von Wright, op. cit., pág. 199. 
situaciones jurídicamente reguladas, las normas del derecho positivo deben en cada caso realizar.

Sería un error creer que la cuestión en torno de la validez intrínseca de los preceptos del derecho sólo tienen que examinarla los órganos de creación jurídica. Pues aun cuando es indudable que alcanza su máxima importancia en conexión con la actividad de tales órganos, sobre todo en el caso del legislador constituyente, los funcionarios judiciales y administrativos no pueden dejar de planteársela, tanto al interpretar las expresiones legales como al enfrentarse al problema de la individualización ${ }^{73}$ de las consecuencias de derecho y, especialmente, al de las lagunas de la ley. ${ }^{74}$

Frente al problema hermenéutico, el de la determinación de la vigencia es siempre cuestión previa, ya que antes de preguntar por el sentido de un precepto, con vistas a su aplicación, hay que establecer si está o no en vigor. Al hacer el análisis de los requisitos condicionantes de la validez jurídicopositiva pudimos percatarnos de que los relativos a la vigencia no se refieren al elemento material de esos preceptos, sino exclusivamente a la forma de su proceso de creación. Mas para decidir si el precepto cuya vigencia se ha comprobado ya es o no aplicable a tal o cual situación concreta, resulta indispensable conocer su contenido y, por ende, interpretar la fórmula empleada por el legislador. Esta tarea sólo puede cumplirse eficazmente cuando se hace uso del llamado método lógico-sistemático, que supone no la interpretación textual, sino contextual de dicha fórmula y, consiguientemente, el conocimiento de los principios axiológicos inspiradores de la actividad legislativa y de las circunstancias y peculiaridades de la cuestión que se pretende resolver.

El segundo de los requisitos condicionantes de ìa vaiidiez -en sentido jurídico-positivo- de las normas del derecho, la ausencia de contradicciones entre el contenido de las de jerarquía diferente, exige, aun en mayor medida, el conocimiento del elemento material de los preceptos entre los que existen relaciones de supra y subordinación y, por tanto, el de los principios axiológicos inspiradores de la actividad legislativa.

Por otra parte, como Schreiber lo señala, el contenido de las normas creadas por el legislador nunca está totalmente determinado. Siempre existe un margen de indeterminación que los órganos aplicadores tienen la misión de llenar, lo que naturalmente supone el estudio de los nexos de cada precepto con los de la institución a que pertenece, así como el análisis de los criterios estimativos que sirvieron de base al autor de la ley.

La necesidad de tomar en cuenta estas directrices es todavía más clara cuando, concluida la labor hermenéutica, el órgano jurisdiccional descubre

73 Cfr. E. García Máynez, Lógica del concepto juridico, cap. I, pág. $4^{6 .}$

74 Cfr. E. García Máynez, Lógica del raciocinio juridico, Fondo de Cultura Económica, México, 1964 , cap. I, secciones 4 y 5 . 
que el caso sometido a su conocimiento no fue previsto por el legislador, por lo que hay que colmar la laguna. Tanto en la hipótesis de que la ley le ordene recurrir primeramente a los llamados principios generales del derecho, ${ }^{75}$ como en el de integración por analogia, el estudio de las valoraciones inspiradoras de la actividad legislativa es igualmente indispensable, ya que el fundamento de la aplicación, a un caso imprevisto, de la disposición relativa a otro análogo previsto, es el principio según el cual dos situaciones esencialmente iguales desde el punto de vista axiológico, deben ser resueltas en la misma forma.

Todo ello revela que el concepto jurídico-positivo y la noción objetiva o intrínseca de validez difieren radicalmente, y que el fundamento de la segunda no puede establecerse por medio de proposiciones sobre hechos, ni derivar jamás de la eficacia de las normas a que tal atributo se refiere, ya que el sentido de éstas consiste en expresar lo que, en las condiciones que su supuesto señala, debe ser juridicamente, aun cuando la conducta de los obligados no concuerde con lo prescrito.

Ni siquiera en relación con el primer concepto puede sostenerse la tesis que equipara las nociones de validez y eficacia, porque, de ser correcta dicha equiparación, habría que equiparar también las de invalidez e ineficacia. Para expresarlo en otro giro: los actos de incumplimiento destruirían la validez de la norma incumplida, ya que la desobediencia en ningún caso puede interpretarse como manifestación del otro atributo. Si el concepto jurídico-positivo de validez y la noción de eficacia fuesen realmente equivalentes, como Schreiber pretende, habría además que sostener que los preceptos que están ya en vigor pero no han sido cumplidos ni aplicados, a nadie pueden obligar, en cuanto aún no tienen eficacia. Por eso admitimos sin reservas las siguientes palabras de Kelsen, escritas por el jefe de la Escuela Vienesa en su obra de 1945: "Any attempt to represent the meaning of legal norms by rules describing the actual behavior of men -and thus to render the meaning of legal norms without having recourse to the concept of 'ought' - must fail. Neither a statement about the actual behavior of those creating the norm, nor a statement about the actual behavior of those subject to the norm, can reproduce the specific meaning of the norm itself." 76

Eduardo García Máynez

76 Cfr. E. García Máynez, Lógica del raciocinio jurídico, cap. I, sección 6.

76 General theory of law and state, Part. one, c, b, pág. 37. 